\section{$16^{\circ}$ \\ ERGODESIGN USIHC CINAHPA}

\title{
DESIGN E INTERFACES DIGITAIS: UMA ANÁLISE DE INSPEÇÃO POR MEIO DO GADI NO SITE METAPIX
}

\section{DESIGN AND DIGITAL INTERFACES: A GADI INSPECTION ANALYSIS ON THE METAPIX SITE}

\author{
Paula Rodrigues ${ }^{1}$, M.Sc. \\ Rafaela Correia ${ }^{2}$, M.Sc. \\ (1) Universidade Estadual de Santa Catarian(UDESC) \\ e-mail: paulailustra@gmail.com \\ (2) Universidade Estadual de Santa Catarian(UDESC) \\ e-mail:rafinhacorreia@yahoo.com.br
}

Palavras-chave: Interface Digital, GADI, Educação Online

\begin{abstract}
Com a disseminação da internet o campo de atuação da educação online vem consolidando o seu papel no cenário brasileiro. $\mathrm{O}$ acesso ao conhecimento vem ganhando cada vez mais espaço devido aos avanços tecnológicos, aliado a disseminação de ferramentas de informação e comunicação, contribuindo para a democratização dos processos de ensino-aprendizagem e de auto formação, com o intuito de garantir qualidade e abrangência dos conteúdos. A partir do uso de interfaces digitais e de recursos midiáticos nesses ambientes é possível observar uma crescente difusão e propagação do conhecimento por meio da produção de cursos online que integram múltiplas mídias, linguagens e recursos. Este artigo analisa a plataforma de ensino de design Metapix, à luz do Guia para Análise do Design de Interface (GADI) de Portugal (2004), com o objetivo de realizar uma inspeção no curso de Design de Superfície e Estamparia, oferecido pelo site Metapix.
\end{abstract}

\section{Key-word: Digital Interface, GADI, Online Education}

With the dissemination of the internet, the field of online education has consolidated its role in the Brazilian scenario. Access to knowledge has been gaining more and more space due to technological advances, together with the dissemination of information and communication tools, contributing to the democratization of teaching and learning processes and self-training in order to guarantee quality and comprehensiveness of content. From the use of digital interfaces and media resources in these environments it is possible to observe a growing diffusion and propagation of knowledge through the production of online courses that integrate multiple media, languages and resources. This article analyzes the teaching platform of Design Metapix in the light of the Guide to Analysis of Interface Design (GADI) of Portugal (2004), with the objective of conducting an inspection in the Course of Design of Surface and Stamping, offered by the site Metapix. 


\section{$16^{\circ}$ \\ ERGODESIGN USIHC CINAHPA}

\section{Introdução}

Os avanços tecnológicos têm provocado amplas transformações no campo da educação. As ferramentas e recursos otimizados devido à tecnologia tem ampliado a prática pedagógica. Nesse contexto, o ambiente de educação online tem ganhado força e espaço.

Segundo Ramos (2010), a educação online pode ser entendida como um tipo de educação à distância que faz uso de recursos de comunicação e mídia por meio da internet.

Todas essas possibilidades se dão em ambientes hipermidiáticos, mediados por interfaces digitais que objetivam facilitar a transmissão do conhecimento. Nesses ambientes é possível identificar o uso de informações textuais, visuais, sonoras, dinâmicas ou estáticas, entre outras.

Aliado as potencialidades desses ambientes, ressalta-se a importância de uma mediação entre o usuário (aluno) e os conteúdos disponibilizados através da interface, nesse caso digital. Segundo Bonsiepe (2015) é essa interface digital que mostra ao usuário como esse deve interagir com os conteúdos e recursos disponíveis.

Para uma melhor interação com essa interface e uma apreensão adequada da informação pelo usuário o design instrucional se faz importante. Segundo Filatro (2008) design pode ser conceituado como o resultado de um processo ou atividade em termos de forma e funcionalidade, com propósitos e intenções definidos e instrução é a atividade de ensino que se utiliza da comunicação para facilitar a aprendizagem. Assim design instrucional pode ser definido como o processo de identificar um problema de aprendizagem e desenhar, implementar e avaliar uma solução para esse problema.

Portanto, este artigo aponta para o desenvolvimento de cursos oferecidos na modalidade presencial que foram convertidos para o formato virtual, desmembrados em tutoriais direcionados para a resolução de problemas $16^{\circ}$ Ergodesign - Congresso Internacional de Ergonomia e Usabilidade de Interfaces Humano Tecnológica: Produto, Informações Ambientes Construídos e Transporte

$16^{\circ}$ USIHC - Congresso Internacional de Ergonomia e Usabilidade de Interfaces Humano Computador

CINAHPA | 2017 - Congresso Internacional de Ambientes Hipermídia para Aprendizagem.

específicos na área do design e de curta duração, a fim de serem disseminados, devido ao seu uso à distância, através da internet.

Para tanto, fez-se uma inspeção do curso de Design de Superfície e Estamparia no Illustrator, oferecido pelo site Metapix, considerando a interface e o uso das hipermídias por meio do Guia para Análise do Design de Interface (GADI), desenvolvido por Cristina Portugal, em sua dissertação de mestrado para o Departamento de Arte \& Design da PUC-Rio em 2004.

\section{Educação Online - E-learning}

A Lei de Diretrizes e Bases da Educação Nacional (LDB n 9.394/96) identifica a Educação à

Distância (EAD) como uma modalidade de ensino, no artigo 80 especifica a possibilidade de uso orgânico da educação à distância em todos os níveis e modalidades de ensino (BRASIL, 1996).

Segundo Arredondo (1999 apud RAMOS, 2010, p. 17) essa modalidade de ensino pode ser caracterizada por não ter supervisão contínua e imediata de professores, pela distância física e temporal entre professor e aluno, por respeitar o ritmo de aprendizagem e pela independência relativa com relação aos tempos de aprendizagem.

O site Metapix, estudo de caso deste artigo, faz uso da educação online na área do design a partir da web por meio de imagens, vídeos e tutoriais que objetivam esclarecer dúvidas e solucionar problemas na área do design e na utilização de softwares gráficos.

Segundo Rosenberg (2002) entre as vantagens proporcionadas pela educação online pode-se identificar: a economia; a ampliação do alcance; a consistência e personalização das mensagens; a facilidade para atualização; a independência de tempo e espaço.

Nesse contexto, vale destacar que uma das evoluções da educação à distância é o E-learning, o qual permite que os alunos sigam diversos percursos de aprendizagem de acordo com o seu ritmo. Com o E-learning, não apenas introduzimos 


\section{$16^{\circ}$ \\ ERGODESIGN USIHC CINAHPA}

uma nova tecnologia para o aprendizado, mas introduzimos uma nova maneira de pensar sobre o aprendizado.

\section{Uso de ambientes virtuais na aprendizagem e o GADI}

As futuras gerações irão conviver cada vez mais com tecnologias de aprendizagem em ambientes de ensino virtuais mediadas por computadores. Portanto, o uso de hipermídias será crescente no meio educacional.

Segundo Silva (2006) a hipermídia, é uma base de dados no qual o usuário navega de informação em informação através de links de forma não sequencial, com total liberdade de construir seu próprio percurso de acesso e utilização da informação minimizando assim a carga cognitiva direcionando-se para uma aprendizagem eficaz.

É importante destacar que, o objetivo de um bom design aplicado as hipermídias para uso educacional é de reduzir a quantidade de processamentos direcionado à interação com o sistema (TAROUCO, 2006).

Para tanto, é necessário que essas hipermídias sejam pensadas em diversos aspectos como Lindermann (1983) nos apresenta desde a simplicidade do texto, passando pela formatação confortável, cabeçalhos e textos pequenos além do uso de imagens e gráficos em ambientes de ensinoaprendizagem, bem como de animação e som.

Portugal (2004) vai tratar de aspectos direcionados ao design de interface que dialogam, diretamente, com a usabilidade em um ambiente de aprendizagem à distância. A autora, em sua dissertação de mestrado, fez um estudo do design como interface de comunicação para ambiente de aprendizado mediado pela internet, por meio de estudos à luz do design, do IHC e da pedagogia.

Em sua investigação, a autora, analisou a atuação do designer como potencializador da informação e da comunicação nos ambientes de aprendizagem mediados pela internet, objetivando o desenvolvimento de interfaces centradas no $16^{\circ}$ Ergodesign - Congresso Internacional de Ergonomia e Usabilidade de Interfaces Humano Tecnológica: Produto, Informações Ambientes Construídos e Transporte

$16^{\circ}$ USIHC - Congresso Internacional de Ergonomia e Usabilidade de Interfaces Humano Computador

CINAHPA | 2017 - Congresso Internacional de Ambientes Hipermídia para Aprendizagem.

usuário e a melhoria dos padrões de ambientes educacionais, tornando o aprendizado à distância mais produtivo e interativo. Esse estudo resultou no GADI, guia que serviu de base para a inspeção realizada neste artigo.

Segundo Portugal (2006) foram realizadas observações sistemáticas a partir de uma oficina e de seus elementos de linguagem visual, para o desenvolvimento do GADI. A qual visava analisar os signos utilizados para representar informações, os modos de captura de telas, as ações e os comentários dos usuários da ferramenta.

A partir daí, sob o ponto de vista do design, da IHC e da Pedagogia e segundo diversos autores, foram relacionados os principais aspectos que devem ser considerados no desenvolvimento de ambientes de aprendizagem, mediados pela internet. Estes aspectos foram separados por itens distribuídos em categorias, sendo elas: Design de Interface, Layout de Tela, Estilo de Interação, Ícones, Tipografia, Layout de Tabelas, Cores e Recursos Multimídia.

De acordo com Portugal (2006), o GADI foi dividido em quatro colunas verticais, a primeira coluna abrange as recomendações à luz do Design, da IHC e da Pedagogia; Na segunda coluna estão disponíveis os aspectos abordados e espaços para comentários e exemplos do ambiente a ser analisado; A terceira coluna avalia os itens e está dividida em outras cinco colunas pelas letras A, B, $\mathrm{C}, \mathrm{D}$ e E, que representam a avaliação dos mais adequados até os menos adequados; Na quarta coluna estão disponíveis os autores que abordaram cada um dos itens como recomendação para aumentar a usabilidade de um sistema (Figura 01).

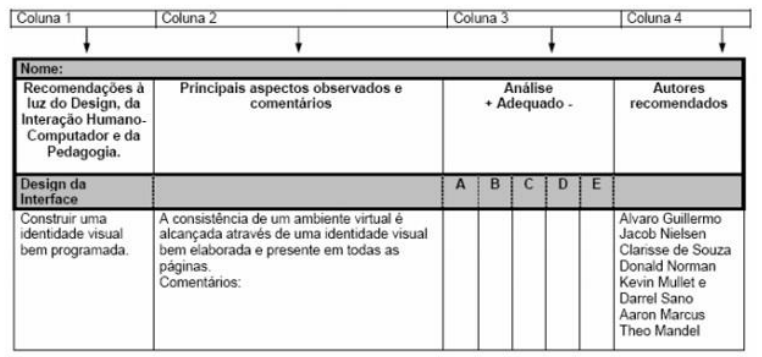

Figura 01 - Guia para a análise do Design de Interface GADI, Portugal (2006). Fonte:

https://infodesign.emnuvens.com.br/public/journals/
Realização:

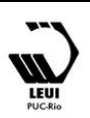




\section{$16^{\circ}$ \\ ERGODESIGN USIHC CINAHPA}

Destaca-se que todos esses aspectos têm por objetivo otimizar a experiência do usuário no ambiente virtual instrucional de aprendizagem, tornando a navegação hipertextual orientada.

\section{Interfaces digitais - O site Metapix}

O entendimento de interface e suas mediações são permeados por diversos pensamentos e discursos. Segundo Bonsiepe (2015) a interface, no ciberespaço, se torna tão importante porque nele tudo é interface, tudo é design: a interface abrange tudo.

Uma vez que, o entendimento de interface permeia a área da comunicação, bem como o meio, a mensagem e a cognição é importante entender como essas possibilidades se dão e, portanto, a adequação da usabilidade dessa interface.

No caso deste artigo, a inspeção foi aplicada ao site Metapix, mais especificamente, ao curso de Design de Superfície e Estamparia no Illustrator.

Portanto, para entender os processos aplicados à interface do site Metapix, é importante destacar que o site é uma plataforma de ensino a distância e de auto formação. Oferece treinamento objetivo, técnico e prático, com conteúdo que integra conceitos e fundamentos do design, através da utilização de ferramentas (softwares gráficos) com foco na atividade profissional.

O conteúdo disponibilizado na plataforma é elaborado pelos designers Lula Rocha, mestre em design, formado em comunicação visual e desenho industrial e Vinicius Braga formado em design de produto. A plataforma possui mais de seiscentos vídeos e disponibiliza três modalidades de curso são eles: Photoshop, Illustrator e Indesign. Em paralelo aos cursos o site também disponibiliza tutoriais, os quais podem ser entendido como uma ferramenta de ensino/aprendizagem que auxilia a aprendizagem exibindo passo a passo o funcionamento de algo.

Em relação ao material de apoio, o site disponibiliza alguns arquivos em PDF ou em imagem, para download, com o intuito de auxiliar $16^{\circ}$ Ergodesign - Congresso Internacional de Ergonomia e Usabilidade de Interfaces Humano Tecnológica: Produto, Informações Ambientes Construídos e Transporte

$16^{\circ}$ USIHC - Congresso Internacional de Ergonomia e Usabilidade de Interfaces Humano Computador

CINAHPA | 2017 - Congresso Internacional de Ambientes Hipermídia para Aprendizagem.

na realização das atividades.

\section{Análise do curso de Design de Superfície e Estamparia oferecido pelo site Metapix à luz do GADI}

Para a realização da inspeção da plataforma de ensino e autoaprendizagem Metapix a partir do GADI, foi selecionado um dos cursos oferecidos, tendo em vista que neste artigo não seria possível realizar uma análise geral e total da plataforma devido ao seu tamanho.

Nesse sentido, o curso escolhido foi Design de Superfície e Estamparia, disponibilizado no curso de Illustrator. Esse curso tem como objetivo o ensino, a criação e o desenvolvimento de estampas no software Adobe Illustrator a partir de uma série de vídeo aula dividida em doze capítulos, (Figura 02). Cada capítulo possui uma série de vídeos, de curta duração que busca ensinar um pouco sobre a temática do curso.

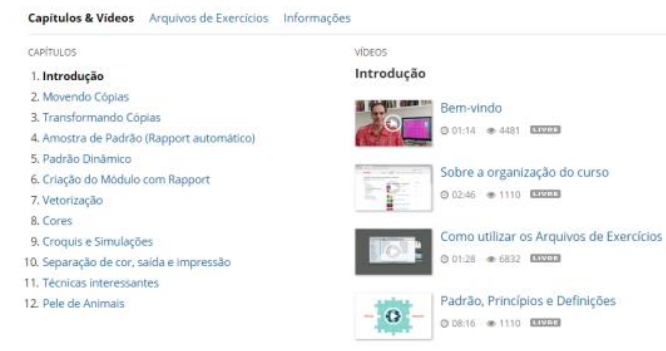

Figura 02 - Curso de Design de Superfície e Estamparia site Metapix. Fonte: https://metapix.com.br/curso/illustratorsuperficie/introducao/-Acesso em 20 de outubro de 2016

A inspeção da interface do curso escolhido, por meio do GADI, foi realizada por três professores de design, que atuam na área do design de moda, do design gráfico e da educação à distância, há mais de cinco anos, tanto no mercado como na universidade. Os professores têm, portanto, experiência e referências suficientes para a validação da inspeção. Vale ressaltar que, a inspeção foi realizada pela internet seguindo parâmetros do GADI.

O GADI possui sessenta e duas recomendações relacionadas à interface divididas em oito categorias. Os valores de gradação para as
Realização:

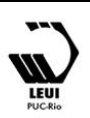




\section{$16^{\circ}$ \\ ERGODESIGN USIHC CINAHPA}

recomendações foram classificados segundo os critérios estabelecidos por Portugal (2006), são eles:

$\mathrm{A}=$ adequado (o item contempla recurso fundamental para uma boa interaçăo com o usuário) $A=$ adequado (o item contempla recurso fundamental para uma boa interaçắo
$B=$ adequado com restriçōes (o item contempla parcialmente recomendaçâ); $\mathrm{C}=$ neutro (o item não está presente ou não é utilizado);

$\mathrm{D}=$ pouco adequado (o item está presente e é mal utilizado);

$\mathrm{E}=$ inadequado (o item está presente e é utilizado de forma inadequada);

Figura 03 - Valores de gradação, Portugal (2006).

Fonte: https://infodesign.emnuvens.com.br/public/journals

Devido à grande quantidade de informações obtidas nas três inspeções, optou-se por compilar os resultados em uma planilha gerando um gráfico (Figura 04), no qual é possível observar as relações entre as categorias analisadas e a frequência que alcançaram nas inspeções feitas pelos três professores de design. As cores do gráfico fazem referências as letras, ou seja, a classificação dos valores de gradação supracitados.

No modelo do GADI apresentado por Portugal (2004), as categorias não possuem um número de recomendações padronizado, por isso algumas categorias são maiores que outras, o que gerou uma oscilação nos resultados apresentados pelo gráfico a seguir.

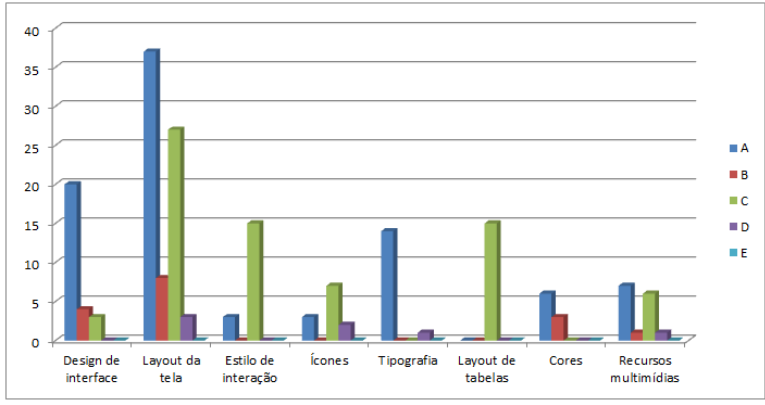

Figura 04 - Tabela de Resultados. Valores de gradação, Portugal (2006). Fonte: do autor, 2016

No gráfico é possível observar que cada categoria teve uma frequência diferente. No caso das categorias Design de Interface, Layout da Tela e Tipografia observa-se que grande parte das recomendações estão de acordo com o guia. Já as categorias Estilo de Interação, Cores e Recursos Multimídia não apresentaram grandes alterações e a categoria Ícones se apresentou deficitária. Por fim, a categoria Layout de Tabelas não apresentou nenhum benefício ao objeto analisado, nesse caso é considerada neutra. $16^{\circ}$ Ergodesign - Congresso Internacional de Ergonomia e Usabilidade de Interfaces Humano Tecnológica: Produto, Informações Ambientes Construídos e Transporte

$16^{\circ}$ USIHC - Congresso Internacional de Ergonomia e Usabilidade de Interfaces Humano Computador

CINAHPA | 2017 - Congresso Internacional de Ambientes Hipermídia para Aprendizagem.

$\mathrm{Na}$ inspeção realizada da interface do curso, algumas das recomendações referentes à categoria Design da Interface são: alcançar a consistência do ambiente virtual, através da otimização e aperfeiçoamento da identidade visual entre todas as páginas de navegação do curso. Adicionar legendas em alguns itens do menu e trabalhar com ícones como uma opção para não usar somente palavras e textos. Disponibilizar um mapa do site orientando sobre a navegação.

Na categoria Layout da Tela, as recomendações são: melhorar o apelo estético-visual das páginas do curso e da plataforma como um todo. No tocante a hierarquia, ela pode ser mais bem desenvolvida, seja por meio da modificação do tamanho das fontes, ou do contraste entre as cores. Outra recomendação é em relação extensão da página, que deve ser diminuída.

Ainda no que diz respeito ao Layout da Tela a navegação entre diferentes arquivos, simultaneamente, deveria ser possível, principalmente, pelo fato da plataforma fazer uso de vídeos. Nesse sentido, seria interessante poder ver um vídeo e acessar outros arquivos, como os exercícios. Em paralelo, o site também poderia trabalhar com mensagens de erro com o intuito de auxiliar ou orientar o usuário, caso este venha a fazer algo de errado durante a navegação.

Tendo em vista que o site é uma plataforma de ensino à distância, a falta de um canal de comunicação entre os usuários é sentida, seja para trocar informações ou para expor os trabalhos realizados, como uma galeria, ou até mesmo para ter uma área do aluno, no qual este pudesse personalizar sua área de estudo.

Por fim, destaca-se a falta de um espaço para tutoria ou para tirar dúvidas. Apesar dos vídeos serem didáticos é interessante ter um feedback, que poderia ser feito pelos instrutores do curso ou até mesmo por outros usuários, se houvesse um canal de comunicação.

Na categoria Ícones, a principal recomendação é de que o site faça uso de ícones, pois não existe nenhum. Todos os menus e itens são representados
Realização:

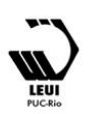




\section{$16^{\circ}$ \\ ERGODESIGN USIHC CINAHPA}

$16^{\circ}$ Ergodesign - Congresso Internacional de Ergonomia e Usabilidade de Interfaces Humano Tecnológica: Produto, Informações Ambientes Construídos e Transporte

$16^{\circ}$ USIHC - Congresso Internacional de Ergonomia e Usabilidade de Interfaces Humano Computador

CINAHPA | 2017 - Congresso Internacional de Ambientes Hipermídia para Aprendizagem. por palavras. Também pode fazer uso de metáforas de interface virtual.

Já na categoria Tipografia, as recomendações são referentes ao uso de caixa alta em textos longos, que poderia ser evitada e ao uso do negrito ou outra forma de destaque para os menus, que poderia ser otimizada, talvez com aplicação de cores. Em seguida tem a categoria Cores que não tem muito destaque na interface do curso e que poderia ser melhor explorada, como uma forma de chamar mais atenção para alguns itens, para hierarquizar informações ou para envolver mais o usuário com o sistema.

Na categoria Recursos Multimídia, as recomendações são de trazer uma galeria junto às páginas do curso com os trabalhos realizados pelos usuários, apresentado assim outras possibilidades de criação além das apresentadas e desenvolvidas pelo instrutor. Outra recomendação seria o uso de animações, uma vez que, o curso faz uso de muitos vídeos, talvez usar uma animação ajudaria no processo de ensino.

As categorias Estilo de Interação e Layout de Tabelas não foram contempladas, pois praticamente todos os seus itens não se aplicaram à inspeção, sendo classificadas como neutras.

A partir dessa análise pode-se constatar que questões de design que se referem ao layout da tela, ao uso de elementos gráficos, ícones, tipografia, cores dentre outros, são tópicos críticos para atender critérios de usabilidade, ou seja, no que se refere à qualidade da interação de sistemas com os usuários. Nesse sentido, a interface do curso se apresenta com algumas carências que podem ser solucionadas no intuito de melhorar a usabilidade e o propósito maior do site que é de proporcionar o ensino e a autoaprendizagem no design.

\section{Considerações Finais}

$\mathrm{O}$ artigo buscou destacar a importância em observar como o ensino do design vem absorvendo as iniciativas que envolvem tecnologia e como essas relações podem ser estabelecidas na otimização desse sistema de ensino/aprendizagem, bem como de auto formação. A relevância deste trabalho reside no crescente uso de tecnologia no ambiente educacional, que tem transformado a maneira pela qual se tem aprendido e ensinado. Porém os recursos tecnológicos, apesar de sua importância e visibilidade, não constituem a característica mais significativa da transformação no ensino. Repensar sua função torna-se, então, uma prioridade na educação.

\section{Referências Bibliográficas}

BONSIEPE, G. (2015). Design: do material ao digital. São Paulo: Blucher.

BRASIL, Lei 9.394. Lei de Diretrizes e Bases da Educação Nacional. Brasília/DF, 2006.

FILATRO, Andréa. Design instrucional na prática. São Paulo: Pearson Education do Brasil, 2008.

LINDERMANN, Helena. Os sistemas do futuro e seus aspectos ergonômicos. In: Boletim DC. Porto Alegre, vol. 4, n.1, jan., 1983.

\section{PORTUGAL, C. Design como interface de} comunicação para ambientes de aprendizado mediados pela internet. Dissertação de Mestrado não publicada, Departamento de Artes \& Design. Pontificia Universidade Católica do Rio de Janeiro, BR, 2004.

RAMOS, D. K. Cursos on-line: planejamento e organização. Florianópolis: UFSC, 2010.

SILVA, C. R. de O. Avaliação de Sistemas de Hipermídia Pedagógica na Perspectiva da Ergopedagogia. In: PEREIRA, A. T. C.; SANTOS, N. dos; ULBRICHT, V. R. Ambientes

Hipermediáticos: volume 1. Rio de Janeiro: Ciência Moderna, 2006. cap. 2, p. 23-36.

TAROUCO, Liane M. R. Alfabetização visual para a redução da sobrecarga cognitiva em material educativo digital. In: PEREIRA, A. T. C.; SANTOS, N. dos; ULBRICHT, V. R. Ambientes Hipermediáticos: volume 1. Rio de Janeiro: Ciência Moderna, 2006. cap. 2, p. 37-48.
Realização:

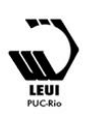

